\title{
Hay Mite Communities in Sheep Farms from French and Spanish Basque Regions with regard to Scrapie Infection
}

\author{
Thorkil E. Hallas ${ }^{*}, 1$, Ana L. Garcia-Pérez ${ }^{2}$, Ana Hurtado², Jesús F. Barandika², Ramon A. Juste ${ }^{2}$, \\ Jean-Marc Arrantz ${ }^{3}$, Stephanie Minery ${ }^{3}$, Lucas Gruner ${ }^{4}$ and Jacques Cabaret ${ }^{4}$ \\ ${ }^{I}$ Institute for Experimental Pathology, University of Iceland, Keldur v/Vesturlandsvegur, IS-112 Reykjavik, Iceland \\ ${ }^{2}$ Department of Animal health, NEIKER- Instituto Vasco de Investigación y Desarrollo Agrario, Berreaga 1, E 48160 \\ Derio (Bizkaia), Spain \\ ${ }^{3}$ Centre Départemental d'Elevage Ovin, F 64130 Ordiarp, France \\ ${ }^{4} U R 1282$ Infectiologie animale et santé publique (IASP), Institut National de la Recherche Agronomique (INRA), \\ F 37380 Nouzilly, France
}

\begin{abstract}
It has been suggested that the mites connected with the decay of stored hay may be involved in the transmission of scrapie, a neurological disorder in sheep. To find out whether there are any obvious differences in the mite fauna in hay that could be related to outbreaks of scrapie in sheep, we analysed the hay fauna from 23 farms in the Basque regions in France and Spain, areas with high and very low incidence of scrapie, respectively. We did find some differences in the composition of the fauna, and a species such as Pygmephorus spp. was more prevalent in scrapie-infected farms, and particularly in highly scrapie-infected farms. The former species is associated with late stages in the biological degradation of stored hay and could be linked to the disease. Besides being the first record of the composition of the hay mite fauna in Spain and France our finding of differences in mite communities in hay from scrapie versus non-scrapie farms is a further indication of the possible association of certain mite species with scrapie.
\end{abstract}

\section{INTRODUCTION}

Mites in hay have been linked to outbreaks of scrapie [1]. Scrapie is the sheep equivalent to Bovine Spongiform Encephalitis (BSE). It is a slowly developing, transmissible, neurological disorder in sheep, and the causative agent is the abnormal isoform $\left(\mathrm{PrP}^{\mathrm{Sc}}\right)$ of the host prion protein [2]. Outbreaks of scrapie probably occur as a result of a combination of the presence of $\mathrm{PrP}^{\mathrm{Sc}}$ and the genetic susceptibility of the sheep affected. Susceptibility to scrapie is governed by polymorphisms of the PrP gene at the codons 136, 154 and 171 [3] and, in this respect, the predominant breeds in the Basque region are similar at both sides of the Franco-Spanish border [3, 4]. Scrapie is now endemic in the milking flocks of the Manech red-faced sheep breed from the French Basque region (Atlantic Pyrenees), whereas a very low incidence of the disease is reported in sheep that have nearly the same genetic constitution (the Latxa breed), in the Spanish Basque region. This suggests that as-yet unidentified environmental factors might be involved in outbreaks of the disease. During a search for possible agents of recurrent scrapie in Iceland it was found, that the mites in stored hay could be carriers of $\operatorname{PrP}^{\mathrm{Sc}}[1,5]$. Storage mites in hay or 'haymites' have been investigated primarily in connection with human work related respiratory diseases $[6,7]$, but

*Address correspondence to this author at the Hojgaardsparken 23, DK 3660 Stenlose, Denmark; Tel: +45 48184157; E-mail: thallas@hotmail.com almost nothing is known about the fauna of hay mites in most countries, including the Basque regions in France and Spain. In order to observe possible links between the species or communities of mites and the occurrence of scrapie in these otherwise genetically similar sheep breeds, we made an initial study of the mite fauna in hay in the French and Spanish Basque regions.

\section{MATERIALS AND METHODS}

\section{Farm Characteristics}

In October 2000, hay samples were collected from farms in the scrapie endemic French Basque region (8 farms with a history of scrapie -FS-, and 2 farms scrapie-free -F-) and from 7 scrapie-free farms in the Spanish Basque region (S). In order to obtain equal sized groups for statistical analysis, in October 2002 we added samples from another six French farms with no history of scrapie (F). The group characteristics of the farms can be read in Table 1. Scrapiefree status was confirmed from the absence of clinical symptoms in the flock, and the absence of signs of scrapie in culled ewes in the last years. Scrapie positive farms (FS) were classified to high (FS1, FS8, FS2, FS6) or low prevalence of the disease. High prevalence means that more than $9 \%$ of the sheep were affected, while less than $3 \%$ affected were considered to be low. These percentages were made up for each farm from maximal annual clinically confirmed cases 1998 - 2002. The distance between the farms was less than $60 \mathrm{~km}$ in each region. 
Table 1. Flock and Management Average Characteristics of Sheep Farms in the Basque Regions of Spain (S; Scrapie-Free) and France (F and FS; Scrapie-Free and Scrapie-Infected, Respectively)

\begin{tabular}{|l|c|c|c|}
\hline Country & Spain & France & France \\
\hline Groups & $\mathrm{S}$ & $\mathrm{F}$ & $\mathrm{FS}$ \\
\hline Number of farms & 7 & 8 & 8 \\
\hline Scrapie maximum incidence in \% 1999-2001 & 0 & 0 & 10.7 \\
\hline \% resistant sheep ARR genotypes in 1999 & 26 & 20 & 26 \\
\hline Adult ewes in the flock & 234 & 240 & 241 \\
\hline Milk (litres per ewe) & 79 & 138 & 120 \\
\hline Cattle per pasture area (ha) & $2 / 14$ & $18 / 25$ & $16 / 27$ \\
\hline Cattle-units per ha & 3.0 & 1.9 & 1.7 \\
\hline Permanent pastures, \% of grazed area & 100 & $<50$ & $<50$ \\
\hline \% Hay bought from other farms & 55.1 & 10.4 & 12.6 \\
\hline
\end{tabular}

\section{Mite Sampling and Identification}

Hay samples were collected manually and put into polyethylene bags. In most of the farms, samples were taken from both the first and second cuts, and a total of 37 samples were collected. Between 40 and $100 \mathrm{~g}$ of hay from these samples were processed in Berlese funnels for at least 8 hours. For identification purposes, some of the mites were stained with Lignin Pink and cleared in lactic acid before being washed with tap water on a suction filter and finally embedded in Hoyers' medium [8] on slides. They were examined under normal phase contrast $\mathrm{x} 100$, and the monograph by Hughes [9] was used as guide for their identification. The remaining mites were dispersed in water in a Petri dish for counting. The mites present in an area corresponding to $10 \%$ of the dish were counted three times under a stereomicroscope at $25 \mathrm{x}$ magnification. The original number of mites in the sample was estimated from the arithmetic mean of these three counts, plus the number of specimens on the corresponding slide. The number of mites $/ \mathrm{kg}$ of hay was calculated from the proportions of the various mite species identified on the slides.

\section{Statistical Analyses of Hay Mite Communities}

The following aspects of the mite communities were investigated: a) the concentrations of mite species in the hay (data transformed to $\log (\mathrm{x}+1)$ to stabilize the variance), $\mathrm{b}$ ) the percentage of each species in the community (data transformed into Arcsine square root to stabilize the variance), c) the species diversity using the species number or Shannon Weaver index [10], $\left(\mathrm{H}^{\prime}=-\sum\right.$ pi Log pi where $\mathrm{pi}=$ number of individuals of species $\mathrm{i} /$ total number of mites. $\mathrm{H}^{\prime}$ ranged from 0 to the natural logarithm of the total number of species in the sample), and d) the presence/absence of the species, using the Farris phylogenetic Hennig86 Program [11]. The concentrations of each species of mite on the three groups of farms (F, FS and S) were compared using the analysis of variance procedures of the SAS package, version 8.0 (SAS Institute, Cary, NC, USA) with the Duncan test for group mean comparison. The proportions of each species were compared using the same procedure.

The Hennig86 software $[11,12]$ has previously been used for describing communities [13] in order to trace their putative historical construction. Briefly, the original community is taken to be devoid of species (ancestral situation $=$ outgroup) and gradually over time, it incorporates new species. Several trees were constructed, each by a single pass, but adding the farms in a different sequence each time. We then applied branch - swapping to each of the trees and finally retained just one tree corresponding to each initial tree. The findings of the analysis are presented in tree form, in which the farms are ordered on the basis of the similarity of their community. In the present paper, the "mite groups" of the farms were established from the tree (and not on the basis of their origin or scrapie status). Each cluster (mite group) of the tree based on mites is examined for scrapie, and then it is identified as low or high scrapie group. The clusters were related to scrapie, either using an analysis of variance of the mite concentrations, or the Fisher exact test for the occurrence of scrapie.

\section{RESULTS}

\section{Number and Species of Mites}

For each farm, only small and non-significant differences were found between hay from first and second cuts with regard to the mite species or the total mite counts, and so the mean value for each farm was used in subsequent analyses. The results for the single farms (Table 2) showed huge variations in the total mite concentrations, ranging from 316 to 68,112 mites per $\mathrm{kg}$ of dry hay.

The total number of mites per $\mathrm{kg}$ of dry hay did not significantly differ between the three types of farms (Table 3).

The Spanish farms had significantly higher concentrations of Blomia freemani, and lower concentrations of Lepidoglyphus destructor and "other acari", than the French farms. Cheletomorpha lepidoptorum and Pygmephorus spp. were significantly more abundant in French scrapie-infected farms and the latter was only found in these farms.

Proportions of species on the French farms (with or without scrapie) and the Spanish farms (Table 4) showed that Acarus siro was the dominant species in the Spanish farms accounting for $31 \%$ of the mites found; significantly lower percentages of this mite were found in the French farms. The proportion of $B$. freemani was significantly higher in Spain than in France. Conversely, the proportion of L. destructor was higher on the French farms, and was only found in one Spanish farm. The Shannon-Weaver index was significantly lower in the Spanish and French scrapie-free farms than in the French scrapie-infected farms. The latter were characterized by the presence of Pygmephorus spp.

\section{Cladistic Analysis of Communities}

Five trees were constructed, but as they were very similar to each other, only one is shown.

Most of the Spanish farms (except S1 and S3) are located in the vicinity of the outgroup, since they harboured fewer 
Table 2. Number of Mites Per Kg of Dry Hay in the Scrapie-Free Sheep Farms in the Spanish Basque Region (S), in the Scrapie-Free Sheep Farms in the French Basque Region (F), and in the Scrapie-Infected Sheep Farms in the French Basque Region (FS)

\begin{tabular}{|c|c|c|c|c|c|c|c|c|c|c|c|c|c|}
\hline $\begin{array}{l}\text { Farm } \\
\text { Code }\end{array}$ & \multicolumn{13}{|c|}{ Number of Mites Per kg of Dry Hay (Means) } \\
\hline S 2 & 1679 & 0 & 420 & 0 & 0 & 0 & 420 & 0 & 0 & 0 & 0 & 0 & 2519 \\
\hline S 3 & 56103 & 1500 & 3473 & 3564 & 0 & 1782 & 0 & 376 & 938 & 376 & 0 & 0 & 68112 \\
\hline S 6 & 0 & 0 & 0 & 0 & 0 & 0 & 402 & 0 & 471 & 0 & 0 & 0 & 873 \\
\hline S 7 & 767 & 0 & 0 & 0 & 0 & 153 & 0 & 0 & 0 & 0 & 0 & 0 & 920 \\
\hline F 1 & 106 & 2114 & 2105 & 0 & 0 & 0 & 1368 & 333 & 0 & 53 & 0 & 0 & 6079 \\
\hline F 2 & 0 & 183 & 23 & 121 & 0 & 8 & 140 & 4 & 0 & 0 & 0 & 12 & 491 \\
\hline F 6 & 0 & 187 & 9 & 0 & 9 & 0 & 103 & 9 & 0 & 0 & 0 & 29 & 346 \\
\hline F 7 & 0 & 136 & 881 & 0 & 136 & 0 & 8000 & 542 & 68 & 0 & 0 & 474 & 10237 \\
\hline F 8 & 345 & 668 & 162 & 0 & 183 & 365 & 0 & 161 & 161 & 0 & 0 & 344 & 2389 \\
\hline FS 1 & 123 & 2686 & 437 & 69 & 0 & 0 & 137 & 54 & 260 & 0 & 191 & 69 & 4026 \\
\hline FS 2 & 172 & 722 & 352 & 0 & 0 & 0 & 181 & 91 & 344 & 0 & 172 & 262 & 2296 \\
\hline FS 3 & 177 & 1486 & 2114 & 441 & 0 & 0 & 265 & 0 & 100 & 0 & 0 & 0 & 4583 \\
\hline FS 4 & 1221 & 3275 & 5548 & 1710 & 0 & 0 & 405 & 243 & 352 & 162 & 0 & 162 & 13078 \\
\hline FS 5 & 0 & 1596 & 1482 & 0 & 2280 & 798 & 342 & 342 & 0 & 912 & 0 & 0 & 7752 \\
\hline
\end{tabular}

Columns: A. Acarus siro L. s.l.; B. Lepidoglyphus destructor (Schrank); C. Tarsonemus Can.\&Fanz; D. Tyrophagus cf putrescentiae (Schrank); E. Chortoglyphus arcuatus (Tropeau); F. Blomia freemani Hughes; G. Cheyletus eruditus (Schrank); H. Cheletomorpha lepidoptorum (Shaw); I. Tydeus Koch; J. Kleemannia plumigera Oud.; K. Pygmephorus Kramer; L. Other Acari; Total =Total mites per kg dry hay.

Table 3. Back-Transformed, Least-Square Means of the Concentration of Each Species of Mites (as Specimens Per Kg Dry Hay) on the Farms and ANOVA Analysis. For Each Species, Different Letters Indicate a Significant Difference in the P Value

\begin{tabular}{|l|c|c|c|c|}
\hline \multicolumn{1}{|c|}{ Mite Concentrations } & Spanish Scrapie-Free & French Scrapie-Free & French Scrapie-Infected & ANOVA (P Values) \\
\hline \hline Acarus siro s. $l$. & 246 & 10 & 27 & 0.2 \\
\hline Lepidoglyphus destructor & $2 \mathrm{a}$ & $429 \mathrm{~b}$ & $1209 \mathrm{~b}$ & 0.0001 \\
\hline Tarsonemus sp. & 149 & 168 & 14 & 0.29 \\
\hline Tyrophagus cf putrescentiae & 5 & 1 & 5 & 0.2 \\
\hline Chortoglyphus arcuatus & 1 & 22 & $2 \mathrm{~b}$ & 0.02 \\
\hline Blomia freemani & $90 \mathrm{a}$ & $25 \mathrm{~b}$ & 0.27 \\
\hline Cheyletus eruditus & 41 & 230 & $133 \mathrm{~b}$ & 0.02 \\
\hline Cheletomorpha lepidoptorum & $69 \mathrm{a}$ & $66 \mathrm{a}$ & 0.09 \\
\hline Tydeus spp. & 12 & 9 & 4 & 0.95 \\
\hline Kleemannia plumigera & 3 & 3 & $11 \mathrm{~b}$ & 0.008 \\
\hline Pygmephorus spp. & $0 \mathrm{a}$ & $0 \mathrm{a}$ & 0.003 \\
\hline Other Acari & 3377 & $55 \mathrm{~b}$ & 0.45 \\
\hline Total mites per kg dry hay & & 1854 & $\mathrm{~b}$ & \\
\hline
\end{tabular}


Table 4. Comparisons of the Species Richness (Number of Mite Species Found on the Farm) and Shannon-Weaver (H') Index of Diversity and Percentages (Back-Transformed, Least-Square Means) of Each Taxon on the French and Spanish Farms. For Each Species, Different Letters Indicate a Significant Difference in the P Value

\begin{tabular}{|c|c|c|c|c|}
\hline Farm Averages & Spanish Scrapie-Free & French Scrapie-Free & French Scrapie-Infected & ANOVA (P-Values) \\
\hline Richness (No of species) & 5 & 7 & 7 & 0.11 \\
\hline Shannon-Weaver index $\left(\mathrm{H}^{\prime}\right)$ & $0.79 \mathrm{a}$ & $1.21 \mathrm{c}$ & $1.47 \mathrm{~b}$ & 0.0002 \\
\hline$\%$ of Acarus siro s. $l$. & $30.77 \mathrm{a}$ & $0.90 \mathrm{~b}$ & $1.84 \mathrm{~b}$ & 0.01 \\
\hline$\%$ of Lepidoglyphus destructor & $0.04 \mathrm{a}$ & $30.77 \mathrm{~b}$ & $29.12 \mathrm{~b}$ & 0.0001 \\
\hline$\%$ of Tarsonemus sp. & 14.38 & 10.26 & 23.05 & 0.37 \\
\hline$\%$ of Tyrophagus cf putrescentiae & 0.16 & 0.42 & 1.29 & 0.62 \\
\hline$\%$ of Chortoglyphus arcuatus & 0.00 & 3.57 & 0.84 & 0.16 \\
\hline$\%$ of Blomia freemani & $9.72 \mathrm{a}$ & $0.43 \mathrm{~b}$ & $0.17 \mathrm{~b}$ & 0.05 \\
\hline$\%$ of Cheyletus eruditus & 7.53 & 24.52 & 5.38 & 0.07 \\
\hline$\%$ of Cheletomorpha lepidoptorum & $0.14 \mathrm{a}$ & $3.57 \mathrm{~b}$ & $6.36 \mathrm{~b}$ & 0.03 \\
\hline \% of Tydeus spp. & 2.57 & 0.56 & 7.74 & 0.17 \\
\hline$\%$ of Kleemannia plumigera & 0.03 & 0.05 & 0.33 & 0.56 \\
\hline \% of Pygmephorus spp. & $0.00 \mathrm{a}$ & $0.00 \mathrm{a}$ & $1.34 \mathrm{~b}$ & 0.02 \\
\hline
\end{tabular}

species than the French farms. They were all different and did not regroup into a cluster. The French farms harboured Tyrophagus spp. as part of their mite communities, and could be roughly divided into two clusters: the Pygmephorus-cluster (FS1, FS8, FS2, FS6 and F6), and the Chortoglyphus arcuatus cluster (FS4, F5, F1, FS7, F8, FS5, F4 and F7), respectively. The association of the presence of Pygmephorus spp. with "high scrapie" farms was highly significant (Fisher exact test; $\mathrm{P}=0.001$ ). These findings are in agreement with the fact that the French scrapie-infected group had a significantly higher number of Pygmephorus spp. than the scrapie-free group (ANOVA, $\mathrm{P}<0.05$ ). The "high scrapie" group could be characterized as harbouring a mite community of $C$. lepidoptorum, Tyrophagus and Pygmephorus.

\section{DISCUSSION}

\section{Mite Faunistics}

The dry stored hay starts a slow decomposition process after harvesting, involving a number of organisms, such as fungi, mites that graze on these fungi, and predators of these mites [14]. The idea that hay mites could be carriers of the scrapie prion protein $\mathrm{PrP}^{\mathrm{sc}}$ has its origin in Iceland [1], where

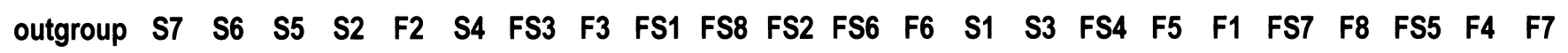

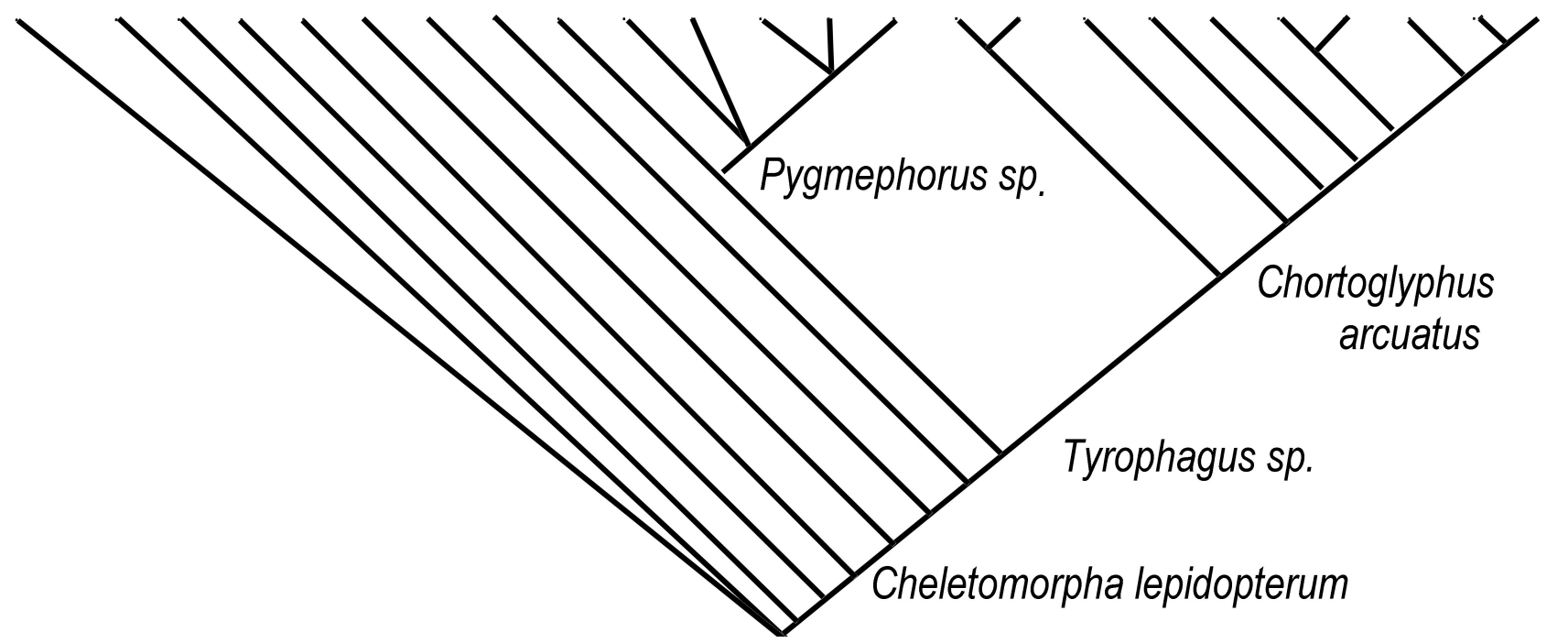

Fig. (1). Phylogenetic tree of the 23 Spanish (S) and French (F) sheep farms (Tyrophagus spp. cluster) based on the composition of their hay mite communities. Scrapie infected farms (FS) are identified by a black dot. 
Table 5. Frequency of the Main Species of Hay Mites in Northern Europe Previously Referenced (in Brackets) and in the French and Spanish Basque Regions Studied in this Work

\begin{tabular}{|l|c|c|c|c|c|}
\hline \% of the Hay Samples in which Species was Present & $\begin{array}{c}\text { Iceland } \\
{[\mathbf{1 5}] \mathbf{1 9 8 1}}\end{array}$ & $\begin{array}{c}\text { Faroe Islands } \\
{[\mathbf{1 6 ]} \mathbf{1 9 8 9}}\end{array}$ & $\begin{array}{c}\text { Finland } \\
{[\mathbf{1 7 ]} \mathbf{1 9 8 2}}\end{array}$ & $\begin{array}{c}\text { Denmark } \\
{[\mathbf{1 8}] \mathbf{1 9 9 0}}\end{array}$ & $\begin{array}{c}\text { Basque Region } \\
\text { This Study }\end{array}$ \\
\hline \hline Acarus siro s.l. & 81 & 55 & 64 & 69 & 61 \\
\hline Lepidoglyphus destructor & 83 & 42 & 64 & 67 & 74 \\
\hline Tarsonemus sp. & 97 & 45 & 55 & 60 & 31 \\
\hline Cheyletus eruditus & 50 & 50 & 45 & 42 & 61 \\
\hline Tydeus spp. & 78 & 50 & 82 & 15 & 61 \\
\hline Kleemannia plumigera & 8 & 8 & 0 & 36 \\
\hline Tyrophagus spp. & 6 & 40 & 36 & 54 & 30 \\
\hline
\end{tabular}

the concentration of mites connected with this process is normally higher than that found in the Basque regions in this study (Table 2). A mean of 50,000 mites $/ \mathrm{kg}$ hay was found in Icelandic farms, and concentrations of more than 1 million mites/ $\mathrm{kg}$ were not unusual [15]. However, hay storage conditions in Northern Europe are quite different from those in the Basque region due to different weather conditions. In Iceland, the grazing period lasts for only four months, and the farmer has to feed his flock indoors for 8 months every year. As a result, hay stores in Northern Europe are generally larger and hay is kept for longer periods (several years) than in the Basque region. However, mites also develop more slowly in Northern Europe, as the decomposition of hay is slow, due to the lower temperatures.

The frequency of the hay mite taxons found in the Basque region indicates that the hay fauna in this area included a core group of hay-inhabiting mites that is almost identical to that found in Northern Europe, including Iceland (Table 5). Quantitatively, these taxa constitute $98-99 \%$ of the specimens found in the Northern European hay (i.e. from Iceland and Denmark) but they only represent $78 \%$ of the total Basque hay mite fauna. This means, that the Basque hay fauna includes additional mite species, which are probably unable to live in Northern European hay because of the different environmental conditions, or because they are interacting with other organisms that do not occur there. Apart from the mesostigmate Kleemannia plumigera, which is a fungal feeder usually associated with concrete, all the other species shown in Table $\mathbf{5}$ occupy separate niches in the mite community of stored hay [7]. The Acarus-siro complex L. destructor and Tyrophagus spp. are fungal feeders with chelicerate mouthparts. In the Basque samples these species seem to be replaced or accompanied by species such as Chortoglyphus arctuatus, B. freemani and Tyrophagus cf. putrescentiae. In addition, the stylet-feeding microbial grazer Tarsonemus sp. seems to be identical to the one found in Northern Europe, and does not appear to be replaced, but other stylet-feeder representatives of the genus Tydeus spp. and Pygmephorus spp. are larger in size than those found in Northern Europe. In the Icelandic hay another Pygmephorus species, $P$. islandicus Sellnick, thought to be associated with small mammals [19], was commonly found in association with biologically old hay [14]. Finally, Cheyletus eruditus is a stylet-feeding predator on other mites. In the Basque hay this species is accompanied by Cheletomorpha lepidoptorum, which is closely related to Cheyletus and has almost identical mouthparts. It is thought to be associated with Lepidoptera for transport, but it is also a known mite predator [9].

There seems to be a greater variability in mite counts $/ \mathrm{kg}$ of hay in the Spanish samples than in the French ones, although differences in the average values were not significant. This may be ascribed to the greater diversity of the sites selected in Spain, where the farms were further away from each other, whereas several of the French sites were neighbouring farms. One of the differences observed between the French and Spanish samples was the greater diversity of mites species found in France. This higher diversity was reflected in the higher Shannon Weaver index in France and was also shown on the cladogram in Fig. (1) (farms rich in mites species were distant from the species-empty outgroup). This difference could be related to the fact that the landscape is less mountainous in France than in Spain.

\section{Mite Communities and the Presence of Scrapie}

The fauna characterization in scrapie-infested farms was assessed using several statistical methods based either on raw data for the mite species, the proportion of species, or the presence or absence of specific species. Pygmephorus spp. was found more frequently associated and in higher proportions (raw data and proportions) in the scrapie-infected farms, which harboured a more diverse fauna. This species is characteristic of biologically old hays, which display high water activity and a low Carbon/Nitrogen ratio [14]. Phylogenetic methods indicated that the mite communities recorded in several scrapie-infected farms consisted primarily of Cheletomorpha lepidoptorum (a mite predator), then Tyrophagus spp. (a fungal feeder) and finally Pygmephorus spp. (microbial grazers). A few scrapie-infected farms recorded communities constituted of Cheletomorpha lepidoptorum, Tyrophagus and Chortoglyphus arctuatus (a fungal feeder). Not all the scrapie-infected farms were associated with the same mite communities, suggesting that half of the cases of scrapie could be linked to the presence of Pygmephorus spp., whereas the remaining cases would be linked to other species or environmental factors. In such a context we might expect the disease agent might be transmitted through infected food or by skin contact with a contaminated 
environment with the mite acting as a carrier [20, 21]. However, the link found in this study between the presence of some hay mites and the occurrence of scrapie, may not be direct, and the mite community be only an indicator of environmental variables suitable for the promotion or persistence of the disease.

\section{ACKNOWLEDGements}

Funding for this study was granted by the European Commission (project FAIR J-CT98 7023: Role of environmental and host factors on the horizontal and vertical transmission of scrapie in naturally infected sheep flocks). The laboratory work with hay samples from scrapie-infected farms was done at Laboratoire Vétérinaire Départemental in Pau, France, and we would like to express our warmest thanks for this hospitality.

\section{REFERENCES}

[1] Wisniewski HM, Sigurdarson S, Rubenstein R, Kascsak RJ, Carp RI. Mites as vectors for scrapie. Lancet 1996; 374: 1114.

[2] Prusiner SB. Prions. Proc Natl Acad Sci USA 1998; 95: 13363-83.

[3] Elsen JM, Amigues Y, Schelcher F, et al. Genetic susceptibility and transmission factors in scrapie. Arch Virol 1999; 144: 431-45.

[4] Hurtado A, Garcia-Pérez AL, Beltrán de Heredia I, et al. Genetic susceptibility to scrapie in a population in latxa breed sheep in the Basque Country, Spain. Small Ruminant Res 2002; 45: 255-9.

[5] Carp RI, Meeker HC, Rubenstein R, et al. Characteristics of scrapie isolates derived from hay mites. J Neurovirol 2000; 6: 137-44.

[6] Ingram CG, Jeffrey TG, Symington IS, Cuthbert OD. Bronchial provocation studies in farmers allergic to storage mites. Lancet $1979 ; 2: 1330-2$.
[7] Hallas TE, Iversen M. Sources of exposure for storage mites in the farming environment. Ann Agric Environ Med 1996; 3: 9-12.

[8] Krantz GW. A Manual of Acarology. 2nd ed. Corvallis Oregon State University Book Stores: Corvallis, Oregon, USA 1978.

[9] Hughes AM. The mites of stored food and houses. Her Majesty's Stationery Office: London, United Kingdom; 1976.

[10] Pielou EC. Ecological Diversity. Wiley: New York, USA 1975.

[11] Farris JS. Hennig 86: a PC Dos program for phylogenetic analysis. Cladistics 1989; 5: 163.

[12] Lipscomb D. Cladistic analysis using Hennig86. George Washington University publications: Washington, USA 1994.

[13] Cabaret J. Relating parasite communities and environments using phylogenetic tools. Parasite 2003; 10: 287-95.

[14] Hallas TE, Gravesen S. Succession of mites and microfungi in stored hay in Iceland. Entomologisk Tidskrift (Stockholm, Sweden) 1987; 108: 23-7.

[15] Hallas TE. Mites of stored hay in Iceland. J Agric Res Iceland 1981; 13: 61-7.

[16] Hallas TE, Solberg H. Mites of stored hay on the Faroe Islands (Acari). Entomologiske Meddelelser (Copenhagen, Denmark) 1989; $57: 151-5$

[17] Terho EO, Leskinen L, Husman K, Kärenlampi L. Occurrence of storage mites in Finnish farming environments. Allergy 1982; 37: 15-7.

[18] Iversen M, Korsgaard J, Hallas TE, Dahl R. Mite allergy and exposure to storage mites and house dust mites in farmers. Clin Exp Allergy 1990; 20: 211-9.

[19] Dastych H, Rack G. Redescription of Pygmephorus islandicus SELLNICK, 1940 (Acari; Heterostigmata). Entomologische Mitteilungen der Zoologische Museum Hamburg 1992; 10: 199-207.

[20] Pammer J, Weninger W, Tschachler E. Human keratinocytes express cellular prion related protein in vitro and during inflammatory skin diseases. Am J Pathol 1998; 153: 1352-8.

[21] Lupi O. Could ectoparasites act as vectors for prion diseases? Int J Dermatol 2003; 42: 425-9. 